\title{
Australian baby boomers switched to more environment friendly modes of transport during the global financial crisis
}

\author{
Md. Kamruzzaman • T. Yigitcanlar • \\ S. Washington · G. Currie · G. Turrell
}

Received: 4 January 2014/Revised: 6 March 2014/ Accepted: 17 March 2014/Published online: 9 April 2014

(C) Islamic Azad University (IAU) 2014

\begin{abstract}
The global financial crisis (GFC) in 2008 rocked economies around the world. Several intermediate outcomes of the GFC included loss of jobs and reduced income. Relatively little research has, however, examined the impacts of the GFC on individual level travel behaviour change. To address this shortcoming, HABITAT panel data were employed to estimate a multinomial logit model to examine mode switching behaviour between 2007 and 2009 of a baby boomers cohort in Brisbane, Australia-a city within a developed country that has been on many metrics the least affected by the GFC. In addition, a Poisson regression model was estimated to model the number of trips made by individuals in 2007, 2008, and 2009. The South East Queensland travel survey datasets were used to develop this model. Four linear regression models were estimated to assess the effects of the GFC on time allocated to travel during a day: one for each of the three travel modes including public transport, active transport, less environmentally friendly transport; and an overall travel time model irrespective of mode. The results reveal that the baby boomers switched to more environmentally friendly travel modes during the GFC.
\end{abstract}

Md. Kamruzzaman $(\bowtie) \cdot$ T. Yigitcanlar $\cdot$ S. Washington School of Civil Engineering and the Built Environment, Queensland University of Technology, 2 George Street, Brisbane, QLD 4000, Australia

e-mail: md.kamruzzaman@qut.edu.au

G. Currie

Institute of Transport Studies, Monash University,

Clayton, VIC, Australia

G. Turrell

School of Public Health and Social Work, Queensland University of Technology, Victoria Park Road, Kelvin Grove, Brisbane, QLD 4059, Australia
Keywords Global financial crisis - Mode choice - Travel behaviour change $\cdot$ Environmentally friendly modes of transport $\cdot$ Brisbane $\cdot$ Australia

\section{Introduction}

This research investigates the travel behaviour impacts of the 2008 global financial crisis (GFC) associated with more disadvantaged groups in a society in Brisbane, Australia. The GFC has been identified as the worst economic crisis since the Great Depression of the 1930s, as it has altered the livelihoods and lifestyles of millions around the world (Bittman and Bradbury 2012; Eichengreen 2011). Research has shown that substantial economic impacts are likely to influence travel behaviour (see, a recent review by Van Cranenburgh et al. 2012). However, little is known about how the GFC-induced economic impacts in livelihoods are reflected by travel behaviour, perhaps due to a lack of relevant data (Yang and Timmermans 2011). Note, however, that fuel prices increased dramatically during the GFC (Hamilton 2009; Hensher and Stanley 2009; Chen et al. 2011). This has led some researchers to study the elasticity of fuel prices in travel demand (Currie and Phung 2007; Hensher and Stanley 2009; Lane 2010, 2012; Merkert and Hensher 2011; Khoo et al. 2012). All of these studies have provided support for a negative effect of fuel price on car travel—car use is reduced by increasing petrol price. An important and remaining question is whether people under economic pressure switch to alternative modes of transport (Van der Waard et al. 2013). Prior research has noted that both the direct and cross-elasticity of fuel price on transit ridership are small (Currie and Phung 2007; Khoo et al. 2012; Lane 2012). Similarly, the cross-elasticity of active transport (AT) with petrol price 
has also been reported to be small (Smith and Kauermann 2011). The findings generally suggest that despite higher fuel prices, people are not willing to give up driving and instead adjust their driving behaviour to conserve gasoline (e.g. fewer and shorter trips) (Yang and Timmermans 2011). However, this generic finding does not apply to all members in a society given that the GFC has been identified to have variable impacts on different groups-i.e. it does not tell us the behavioural dynamics of different groups in a society due to the GFC. If elasticities are modelled as fixed effects, then the average elasticity may fail to capture an affect felt by disadvantaged groups (see Duvarci and Yigitcanlar 2007; Duvarci et al. 2011). So a research approach might be to test random effect elasticities or isolate disadvantaged groups and examine their elasticities.

Despite relatively little research focused on travel behaviour, impacts of the GFC have been measured in different disciplinary areas. The GFC started because of a threat of melting down the subprime mortgage market in the USA (Murphy 2011). This consequently triggered a collapse of confidence in credit markets around the globe (Chesters 2010). Noted day-to-day impacts of the GFC in the literature included but not limited to: changes in total income; changes in usual hours worked; loss of jobs (e.g. particularly by migrants, ethnic minority groups, and low socio-economic groups) (Blakely and McLeod 2009; Koser 2010; Buckley 2012); cease job searching (Verick 2012); dissatisfaction with financial position and poorer perceptions of job security (Chesters 2010); and uncertainty and stress for individuals around retaining employment, the continued viability of businesses and safety of investment (Colley 2012). Kendig et al. (2013) found that the baby boomers in Australia (aged 50 to 64 years in mid-2009) planned to postpone retirement during the GFC or, if they had recently retired, were considering a return to work. Other studies found a changing time use pattern of individuals during the GFC. People significantly increased their time investment in education at the expense of production time (Ironmonger 2012). These intermediate outcomes again acted as the processes leading to a number of other undesirable outcomes. For example, unemployment has been associated with increased self-harm and suicide, and decreased mental health status (Karanikolos et al. 2013). Despite being employed, a reduction in income forced individuals to cut expenditure which resulted in malnutrition (unaffordability of food-food security), household crowding (due to a shift to lower quality but more affordable accommodation). Reduced income has also been associated with the affordability of health care (e.g. prescription, over the counter medicine, time off work) (Blakely and McLeod 2009). Employees made significant changes to their retirement savings investment choices in response to the GFC (Gerrans 2012). Evidences from the Netherlands show that tourists economise their behaviour by shortening vacations and changing destinations (Bronner and de Hoog 2011).

Many of the above outcomes of the GFC (e.g. reduced income, loss of jobs, driving cessation, poorer health) have been identified as significant predictors of travel behaviour change. For example, Kamruzzaman et al. (2013) have shown that individuals with better health are more likely to make a modal shift to AT. Life events (e.g. new job, changes in employment status, residential mobility) have usually been identified as triggers for a modal shift (Yigitcanlar et al. 2007; Chatterjee et al. 2013). Research has also shown that increased care responsibilities are associated with higher levels of car usage (Turner and Niemeier 1997; Currie and Delbosc 2011). Generally, individuals with a higher level of income are less likely to make a modal shift from the car (Curtis and Headicar 1997). Using pseudo-panel data, Dargay (2007) modelled the effects of income changes on car travel in the UK. This study found that income has a positive influence on car travel, and the effect of rising income is greater than that of falling income. In contrast to car usage, note, however, that income has dual effect on public transport patronage as evident in Holmgren (2013). Higher income leads to higher utilisation of public transport services directly. However, higher income also leads to an increase in car ownership, which consequently reduces the level of public transport (PT) usage. When these two effects are combined together, the total income effect is closer to zero on PT patronage. A comprehensive study on the impact of socio-demographic changes on travel behaviour has been reported by Scheiner and Holz-Rau (2013) using three waves of the German mobility panel data (1994-2008). The study reported that despite the overall mode choice pattern remained the same over the period, a significant change occurred 'under the surface', as a result of life course changes, reflected by attributes of individual and household socio-demographics and residential location. More specifically, the study has reported that entering the labour market results in more driving and decreased shares of trips made as a car passenger, or on foot. In contrast, leaving the labour market (without retiring) results in more walking and less PT use. The study has also reported that retirement from jobs results in less driving and more non-motorised travel.

Australia possesses a rather interesting case associated with the GFC. The impacts of the GFC are less pronounced in Australia than other developed countries (Redmond et al. 2013). The GFC slowed down Australian economic growth but did result in stagnation, the unemployment rate increased but at a lower rate with comparable nations (Saunders and Deeming 2011). For example, the unemployment rate for Australian baby boomers rose 
from $2.7 \%$ in 2007 to $3.3 \%$ in 2010 , whereas in the USA, the comparable increase was from 3.1 to $7.1 \%$ (Kendig et al. 2013). In addition, using pre-GFC (2006) and post-GFC (2010) survey data, Saunders and Wong (2012) found little impact of the GFC on income and deprivation in Australia. Petrol prices increased from around AU\$1.2/L in 2007 to over AU\$1.60/L in 2008 and then return back to AU\$1.20 in 2009 (Dodson and Sipe 2008; Hensher and Stanley 2009). The strong economic recovery in Australia after the shock of the GFC has been attributed to both the massive resources boom driven by demand from China and the actions of the then newly elected Labour government (e.g. providing stimulus package directly to the low income families, generous first home owner grants that reinflated the housing-finance system) (Kendig et al. 2013; Redmond et al. 2013). Even though the initial impact of the GFC was much weaker in Australia, it was not totally isolated, since unemployment rose, investment and superannuation returns fell, retired Australians were less satisfied with their financial position, employed people were becoming concerned about job security, and a long boom in housing prices had stalled (Chesters 2010; Mountford 2011; Murphy 2011; Bittman and Bradbury 2012). However, these outcomes are less pronounced for people who experienced a loss in investment because they may have generally higher incomes, and the association of change in income with change in behaviour is much weaker at high incomes (e.g. diminishing marginal returns) (Blakely and McLeod 2009). This makes it all the more important to understand the relationship of the crisis on household and family well-being and consequently on travel behaviour outcomes and to understand how policies might be able to offset the impacts of further travel behavioural uncertainty.

Based on the previous discussion, the objective of this research is twofold: first, to investigate whether there are associations between the GFC and travel behaviour change; and second, if an association exists, to identify the relative influences of the GFC on different groups in terms of travel behaviour. This study was conducted in the local government area of Brisbane (capital city of the State of Queensland) and is based on data collected in 2007 and 2009 from a representative sample of residents aged 40-65. These baby boomers (born between 1946 and 1965) were selected because this cohort has been a focus of transport policy in Australia particularly due to their better health, increased wealth and car oriented lifestyle (Alsnih and Hensher 2003). Speculation also prevails that this generation will be more active and making more trips than previous generations when they become older (Currie and Delbosc 2010). As a result, it would be an interesting case to observe how different groups within this cohort behave in a crisis.

\section{Materials and methods}

Data

Three types of data have been used in previous studies in order to model the dynamics of travel behaviour: aggregate time series data; repeated cross-sectional data; and panel data-i.e. surveys of the same individuals over time (Dargay 2007). Most of the aggregate time series data contain limited variables in order to understand behavioural differences between groups. Repeated cross-sectional data provide a viable alternative to the aggregate time series data. These datasets are also available for longer periods (national travel surveys are the most obvious examples). However, it is difficult to monitor changes in behaviour over time using this type of dataset because they are not collected from the same individuals over the periods. Consequently, panel surveys reflect the preferred option for modelling the dynamics of behaviour at the individual level (Kamruzzaman et al. 2013). However, panel data are rarely available in transport research (Bhat and Guo 2007); and when and where they exist, their spatial and temporal coverage is often quite limited (Dargay 2007). This research overcomes these weaknesses of data and utilises both panel and repeated cross-sectional data to investigate the links between the GFC and travel behaviour.

\section{HABITAT panel survey data}

This research used the HABITAT (How Areas in Brisbane Influence HealTh and AcTivity) panel survey data to monitor changes in mode choice behaviour of individuals/ groups during the GFC. The HABITAT survey collected data in three phases $(2007,2009$, and 2011) from 11,036, 7,866 , and 6,901 adults, respectively (aged between 40 and 70 years) living in 200 census collection districts (CCDs) in Brisbane. The baseline survey (2007) was conducted using a multi-stage probability sampling technique. First, a stratified random sample technique was used to select the 200 CCDs, and from within each CCD, a simple random sample was then drawn (Burton et al. 2009; Turrell et al. 2010). The survey was purposely designed to examine changes in the health and related behaviours of a 'baby boomer' cohort (born between 1946 and 1965), and as a result, younger age individuals were not included. This paper used data from the 2007 (pre-GFC) and 2009 (postGFC) version of the surveys and includes 6,692 individuals who participated in both phases. This analytic sample was obtained by excluding missing cases. The baseline sample of the survey was representative of wider population in Brisbane for this age cohort (Turrell et al. 2010).

Respondents were asked to indicate '...on most weekdays (Monday to Friday), which type of transport do you 
mainly use to get to and from places?' in both survey periods. They were given five options to choose from: (a) public transport; (b) car or motorcycle; (c) walk; (d) bicycle; and (e) other. The walk and bicycle modes were combined together to represent AT. Respondents were also instructed to select only one option from the above. In the 2009 survey, respondents were also asked to indicate whether they 'became unemployed', 'retired from work', 'reduced hours at work', 'experienced increased financial difficulties', and 'experienced increased care responsibility at home' between the periods and were used as independent factors. These factors are clearly related to the GFC outcomes as discussed earlier. Respondents' socio-economic data were also collected as a part of the surveys and were used as controlling factor in order to identify the associations between the independent factors and mode shift behaviour.

\section{South East Queensland travel survey}

In the HABITAT dataset, the variable representing mode choice behaviour is rather crude. A limitation of the form of response coding is that the 'main' mode (amongst 5) used $26 \%$ of the time or $100 \%$ of the time would be coded exactly the same by a respondent (Kamruzzaman et al. 2013). It is possible that mode shifts occurred, yet a 'primary' or 'main' mode did not shift for a respondent. A more precise measure such as number of trips or vehicle kilometres of travel by mode provides an opportunity for more indepth analysis and offer additional insights. As a result, this research used the South East Queensland travel survey (SEQTS) data to monitor behavioural changes more precisely. The SEQTS collects repeated cross-sectional data since 1992. The 2009 was the latest version available during the preparation of this manuscript. The survey collects selfreported travel diary data for a single day from respondents of all ages. The SEQTS employed a similar multi-stage sampling procedure whereby CCDs were randomly sampled first and then households were randomly sampled within the CCDs, and the SEQTS is the main source of data on personal travel in South East Queensland. The SEQTS data have long been used for decision making on transport infrastructure and services worth billions of dollars (Queensland Government 2010). This research used the 2007 (pre-GFC), 2008 (during GFC), and 2009 (post-GFC) version of the surveys. In addition, only respondents who lived in Brisbane and aged 40 and over were retained for analysis in order to match with the HABITAT dataset. Further refinement was made by excluding respondents who reported trips on weekends. These exclusions resulted in an analytic sample of 12,535 individuals for the entire periods $(2,864,2,758,6,913$ individuals in 2007, 2008, 2009, respectively).

Four variables were analysed to monitor travel behaviour changes from the SEQTS data: number of trips made per day, time spent (min) for travelling in a day, total distance travelled in a day, and time spent for travelling by mode in a day. The originally collected 11 travel modes were reclassified into PT (e.g. train, ferry, public bus, and school bus), AT (e.g. walk, and cycle), less environmentally friendly transport (LEFT) (e.g. car driver, car passenger, taxi, and motorcycle), and other. A number of socio-demographic factors were also collected as a part of the SEQTS which were used as controlling factors in this research. These included the following: household size; household structure; home-ownership status; type of dwelling; number of cars, motorbikes, bicycles in households; age; gender; country of birth; drivers' license; income; and employment. These variables have a significant impact on mode choice behaviour in this context (Kamruzzaman et al. 2013, 2014).

\section{Methods}

\section{HABITAT data analysis}

The HABITAT dataset was used to identify associations between the GFC-induced independent factors (e.g. loss of job) and changes in mode choice behaviour between 2007 and 2009. As a result, a new multi-chotomous 'mode switch' variable was created with five categories by comparing respondents' chosen modes in 2007 and 2009. The categories are as follows: unchanged, switched to PT, switched to AT, switched to LEFT, and switched to other. This means that if individuals did not change mode between the periods, an 'unchanged' category was added. The remaining individuals were classified based on their switched mode irrespective of their original modes in order to increase the degree of freedom because $88.5 \%$ individuals did not change mode at all. Given the multi-chotomous nature of the dependent 'mode switch' variable, a multinomial logistic regression (MNL) model was estimated to assess the relationship between GFC-induced independent factors and mode shift behaviour. The 'unchanged' category was used as a reference category in this model. Given that the changed behaviour is not only dependent on changed circumstances but also of a factor of their 'base' values (Meurs and Haaijer 2001; Krizek 2003), therefore, respondents' socio-demographics in 2007 were also included as controlling factors in this model.

\section{SEQTS data analysis}

Given that the SEQTS datasets were repeated cross-sectional observations, it was not possible to monitor changes in travel behaviour at the individual level. However, the datasets served complimentary purposes to assess: (a) whether the number of trips made and the travel times/distances are significantly different in 2008 and in 2009 when compared to 
that in 2007 (pre-GFC period) and (b) whether the behaviour varies for different socio-economic groups over the periods (pseudo-panel analyses). A 'GFC' categorical variable was created with three classes (2007-pre-GFC, 2008-during GFC, and 2009 - post-GFC) and was used as an independent factor for the longitudinal monitoring of travel behaviour. Figure 1 shows the distribution of the number of trips made by respondents in the survey day. The distribution is strongly skewed to the right and approximated by a Poisson or negative binomial. In addition, the number of trips variable represents count data. As a result, a Poisson regression model was estimated in Stata in order to investigate the impact of the GFC on the number of trips (Washington et al. 2010). The collected socio-demographic factors were also included in the model as controlling factors.

The correlation between time spent (min) travelling in a day and total distance travelled in a day was strongly positive (0.724). As a result, only the time spent (min) travelling in a day is reported in this paper, as journey time captures more complexity in travel behaviour of different groups compared with journey distance (Hine and Kamruzzaman 2012). Given that the travel time variable is continuous, a linear regression model was estimated to investigate the differences between the periods. However, the distribution of the travel time data was found to be skewed to the right (Fig. 2a). As a result, a natural log transformation of the data was made based on the literature (Cao et al. 2007). The transformed data were found to be approximately normally distributed (Fig. 2b). Despite the skewness $(-0.236)$ and kurtosis $(-0.145)$, statistics were close to 0 suggesting the evidence of normality, note, however, that the Kolmogorov-Smirnov test shows a statistically significant poor fit. Consequently, a linear regression model was estimated using this transformed data as a dependent variable which was regressed using the

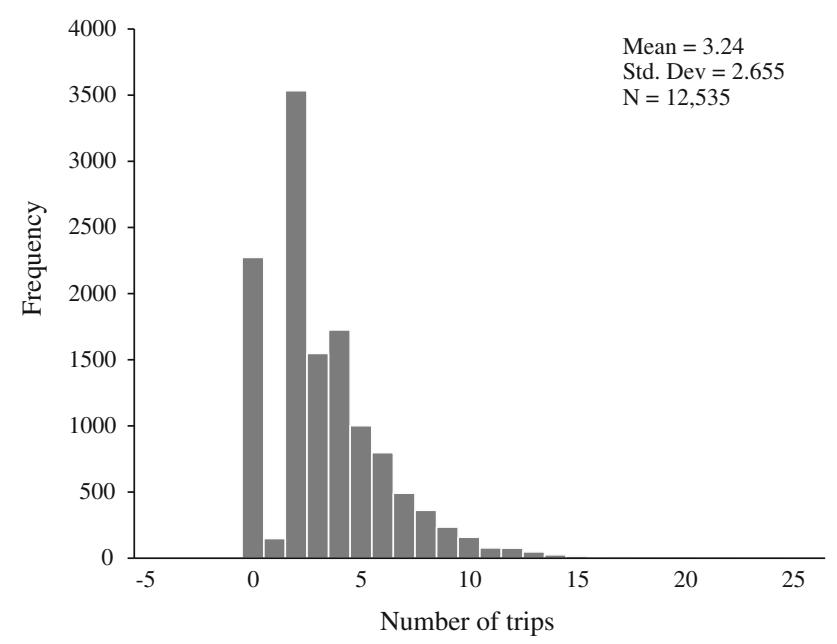

Fig. 1 Distribution of the number of trips made by the respondents in the SEQTS
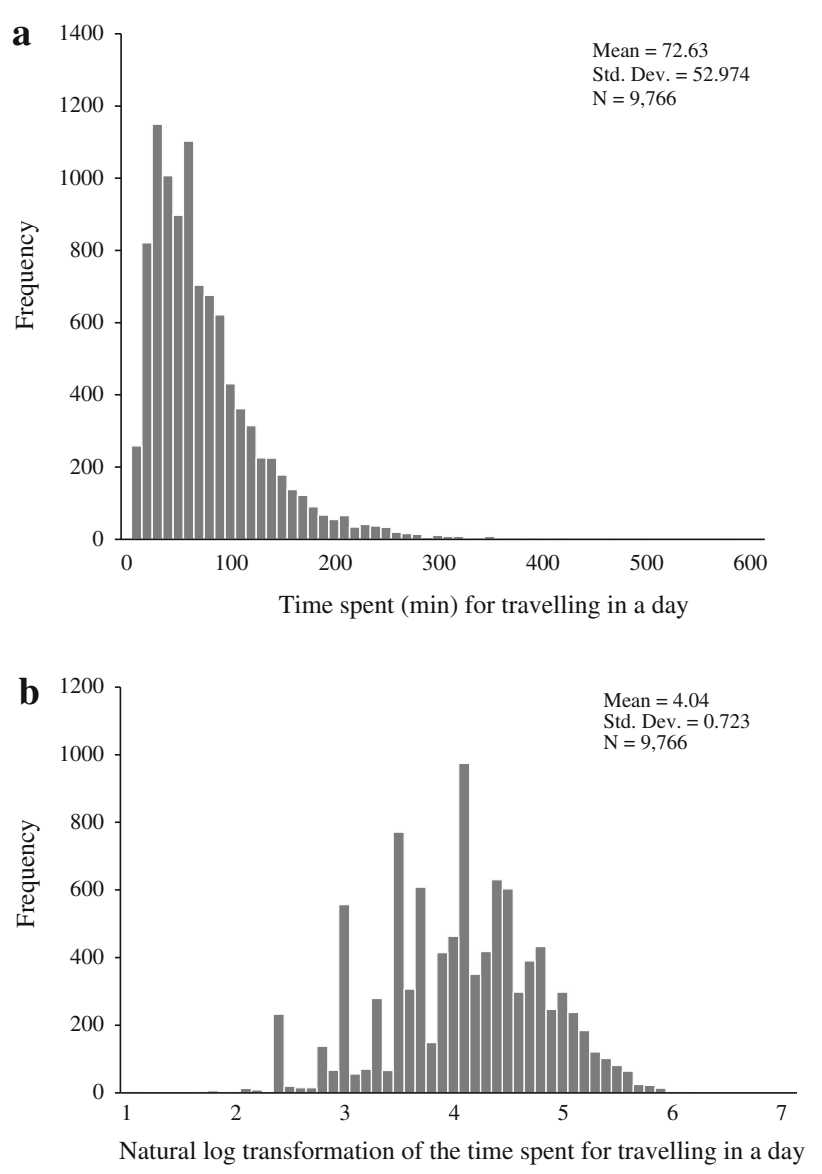

Fig. 2 a Distribution of travel time in a day. b Lograthmic transformation of the distribution of travel time in a day

GFC variable as an independent factor, also controlling for socio-demographic of the respondents. Note that a reduced sample size $(9,766)$ was used for this analysis, since respondents who did not make any trips during the travel day were excluded from this analysis.

In addition to the overall time spent for travelling model, three additional linear regression models (one for each of the PT, AT, and LEFT mode) were estimated in order to investigate variations in mode choice over the periods. Time spent (min) travelling in a day associated with each mode was log-transformed and regressed by the GFC factor, also controlling for socio-demographics. Therefore, these models complement the mode choice model as was estimated based on the HABITAT datasets.

\section{Results and discussion}

Association between the GFC-induced socio-economic outcomes and mode shift

Table 1 shows the results found from the multinomial logistic regression model of mode switch behaviour. It 
shows that the odds of switching to PT were significantly (1.6 times) higher for individuals who became unemployed between the periods. In contrast, individuals who retired or reduced their working hours were significantly more likely to switch to the LEFT. Retired individuals were also found more likely to switch to AT. Individual who experienced financial hardship were 1.5 times more likely to switch to PT. Similarly, individuals whose care responsibility increased at home were significantly less likely to switch to the car.

Correlations between the GFC and the number of trips made

Table 2 shows the results found from the Poisson regression model of the number of trips made by the individuals over the study period. The findings clearly shows that all else being equal, the baby boomers made a significantly fewer number of trips in 2008 and in 2009 compared to that of in 2007 (Table 2). A significantly reduced number of trips were also evident for couples with no children, living in other types of residences, older aged groups, and individuals with lower income brackets. The effect of income, particularly lower income households on travel, confirms along with the lack of significant effect of higher income households that economically disadvantaged households are most affected by the GFC.

Links between the GFC and travel time

Respondents not only made fewer trips over the GFC as identified in Table 2, they spent significantly less time travelling in 2009 compared to 2007 (Model 1, Table 3). This difference is mainly attributed to a significant reduction in car (LEFT) travel time in 2009 (Model 2, Table 3) because Model 3 in Table 3 shows that respondents' PT usages increased significantly in 2009. No overall difference in time spent travelling was observed between 2007 and 2008. This is also true in case of time spent travelling by the LEFT between the periods. However, the odds of using the PT were found to be higher in 2008 compared to 2007, although the odds of AT usage were lower in 2008. Again, older aged people and individuals with a lower level of income spent significantly less time travelling.

Implications of the findings for the environment

The findings from the previous sections clearly indicate that a significant association exists between economic

Table 1 Results from the multinomial logistic regression model showing the odds ratios (ORs) associated with mode shift behaviour of respondents subjected to the GFC

\begin{tabular}{|c|c|c|c|c|}
\hline \multirow[t]{2}{*}{ Explanatory factors } & \multicolumn{4}{|c|}{ Dependent variable: shifted mode between 2007 and 2009 (ref: unchanged) } \\
\hline & $\begin{array}{l}\text { ORs: switched } \\
\text { to LEFT }\end{array}$ & $\begin{array}{l}\text { ORs: switched } \\
\text { to PT }\end{array}$ & $\begin{array}{l}\text { ORs: switched } \\
\text { to AT }\end{array}$ & $\begin{array}{l}\text { ORs: switched } \\
\text { to other modes }\end{array}$ \\
\hline \multicolumn{5}{|l|}{ Change variables (2007-2009) } \\
\hline Became unemployed: yes (ref: no) & 1.010 & 1.606 & 1.485 & 0.722 \\
\hline Retired from work: yes (ref: no) & 2.119 & 0.785 & 1.713 & 1.718 \\
\hline Reduced hours at work: yes (ref: no) & 1.448 & 1.129 & 1.067 & 1.208 \\
\hline Increased financial difficulties: yes (ref: no) & 1.196 & 1.452 & 1.020 & 0.401 \\
\hline Increased care responsibility at home: yes (ref: no) & 0.729 & 0.846 & 1.113 & 0.199 \\
\hline \multicolumn{5}{|l|}{ Base variable (2007) } \\
\hline Full-time employed (ref: non-working) & 1.559 & 0.992 & 0.739 & 0.746 \\
\hline Female (ref: male) & 1.087 & 1.272 & 0.661 & 0.530 \\
\hline Age in years & 0.984 & 0.975 & 0.967 & 0.985 \\
\hline Car availability: yes sometime (ref: yes, always) & 5.349 & 2.474 & 3.416 & 1.488 \\
\hline Car availability: no (ref: yes, always) & 2.498 & 2.428 & 3.476 & 3.730 \\
\hline Car availability: do not drive (ref: yes, always) & 0.904 & 2.616 & 5.788 & 5.333 \\
\hline Education: graduate (ref: up to year 12) & 1.116 & 1.262 & 1.120 & 0.323 \\
\hline Household size & 0.862 & 0.967 & 0.879 & 0.945 \\
\hline Country of birth: other (ref: Australia) & 0.743 & 1.239 & 1.046 & 1.390 \\
\hline-2 Log likelihood & & & & $5,567.643$ \\
\hline Chi-square & & & & 285.356 \\
\hline Pseudo $R^{2}$ (Nagelkerke) & & & & 0.07 \\
\hline$N$ & & & & 6,692 \\
\hline
\end{tabular}

Italicized coefficients are not significant at the 0.05 level 
Table 2 Poisson regression analysis results showing the differences in number of trips made between different years

\begin{tabular}{|c|c|c|c|c|c|c|}
\hline \multirow[t]{2}{*}{ Explanatory factors } & \multicolumn{6}{|c|}{ Outcome variable: number of trips made on the travel day } \\
\hline & IRR & Std. Err. & $z$ & $P>z$ & {$[95 \% \mathrm{CI}]$} & \\
\hline \multicolumn{7}{|l|}{ Year (ref: 2007-pre-GFC) } \\
\hline 2008—during GFC & 0.95 & 0.01 & -3.41 & 0.00 & 0.92 & 0.98 \\
\hline 2009—post-GFC & 0.95 & 0.01 & -4.45 & 0.00 & 0.92 & 0.97 \\
\hline Household size & 1.04 & 0.01 & 6.75 & 0.00 & 1.03 & 1.05 \\
\hline \multicolumn{7}{|l|}{ Household structure (ref: sole person) } \\
\hline Couple with no kids & 0.93 & 0.01 & -5.29 & 0.00 & 0.91 & 0.96 \\
\hline Couple with kids & - & - & - & - & - & - \\
\hline Single parent & 1.09 & 0.03 & 3.66 & 0.00 & 1.04 & 1.14 \\
\hline Other & 0.87 & 0.02 & -7.80 & 0.00 & 0.83 & 0.90 \\
\hline \multicolumn{7}{|l|}{ Home ownership (ref: owner) } \\
\hline Rented & - & - & - & - & - & - \\
\hline Other & - & - & - & - & - & - \\
\hline \multicolumn{7}{|l|}{ Type of dwelling (ref: separate house) } \\
\hline Flat or apartment & 1.06 & 0.02 & 2.70 & 0.01 & 1.02 & 1.10 \\
\hline Townhouse & - & - & - & - & - & - \\
\hline Other & 0.82 & 0.08 & -2.10 & 0.04 & 0.69 & 0.99 \\
\hline Number of cars in household & - & - & - & - & - & - \\
\hline Number of motorbikes in household & - & - & - & - & - & - \\
\hline Number of bicycles in household & 1.05 & 0.00 & 14.45 & 0.00 & 1.05 & 1.06 \\
\hline Age (continuous) & 0.99 & 0.00 & -9.77 & 0.00 & 0.99 & 1.00 \\
\hline Female (ref: male) & 1.07 & 0.01 & 5.64 & 0.00 & 1.04 & 1.09 \\
\hline Country of birth: other (ref: Australia) & 0.95 & 0.01 & -4.46 & 0.00 & 0.93 & 0.97 \\
\hline Car licence: yes (ref: no) & 1.96 & 0.06 & 22.31 & 0.00 & 1.84 & 2.07 \\
\hline Motorbike licence: yes (ref: no) & 1.05 & 0.02 & 2.82 & 0.01 & 1.02 & 1.09 \\
\hline Other licence: yes (ref: no) & 0.94 & 0.02 & -2.66 & 0.01 & 0.90 & 0.98 \\
\hline Licence: some licence (ref: no licence) & - & - & - & - & - & - \\
\hline \multicolumn{7}{|c|}{ Personal income in week (ref: $\$ 1,600$ and higher) } \\
\hline$\$ 1,000-\$ 1,599$ & - & - & - & - & - & - \\
\hline$\$ 600-\$ 999$ & - & - & - & - & - & - \\
\hline$\$ 0-\$ 599$ & 0.88 & 0.01 & -9.52 & 0.00 & 0.86 & 0.91 \\
\hline Zero or negative income & 0.82 & 0.02 & -7.53 & 0.00 & 0.77 & 0.86 \\
\hline \multicolumn{7}{|l|}{ Employment status (ref: non-working) } \\
\hline Full time & 0.91 & 0.01 & -5.75 & 0.00 & 0.88 & 0.94 \\
\hline Part time & 1.08 & 0.02 & 4.39 & 0.00 & 1.04 & 1.11 \\
\hline Casual & 1.06 & 0.02 & 2.89 & 0.00 & 1.02 & 1.11 \\
\hline Log likelihood & & & & & & $-29,104.10$ \\
\hline Pseudo $R^{2}$ & & & & & & 0.05 \\
\hline$N$ & & & & & & 12,535 \\
\hline
\end{tabular}

Dashed coefficients are not significant at the 0.05 level

stress introduced around the time of the GFC and travel behaviour changes. In particular, the GFC was associated with a shift in the use of public transport and a reduced level of personal vehicle usage. An important question is whether these travel behavioural changes could have a positive impact on the natural environment. This issue is discussed in the remainder of this section.
Transport has been identified as an enabler of economic growth and social sustainability because it enhances mobility, thereby increasing accessibility to goods and services and consequently reduce geographical disparity in various sectors (e.g. health, employment, education) (Howarth and Polyviou 2012; Kamruzzaman and Hine 2012; Dur and Yigitcanlar 2014). In contrast, transport adversely 
Table 3 Linear regression analysis results showing the differences in travel time between different years

\begin{tabular}{|c|c|c|c|c|c|c|c|c|c|c|c|c|}
\hline \multirow[t]{2}{*}{ Explanatory factors } & \multicolumn{3}{|c|}{$\begin{array}{l}\text { Model 1: natural log } \\
\text { transformation of total } \\
\text { travel time }\end{array}$} & \multicolumn{3}{|c|}{$\begin{array}{l}\text { Model 2: natural log } \\
\text { transformation of LEFT } \\
\text { travel time }\end{array}$} & \multicolumn{3}{|c|}{$\begin{array}{l}\text { Model 3: natural log } \\
\text { transformation of PT } \\
\text { travel time }\end{array}$} & \multicolumn{3}{|c|}{$\begin{array}{l}\text { Model 4: natural log } \\
\text { transformation of AT } \\
\text { travel time }\end{array}$} \\
\hline & $B$ & $\beta$ & $t$ & $B$ & $\beta$ & $t$ & $B$ & $\beta$ & $t$ & $B$ & $\beta$ & $t$ \\
\hline Constant & 4.50 & & 64.14 & 2.03 & & 26.53 & 1.21 & & 18.10 & 0.76 & & 12.78 \\
\hline \multicolumn{13}{|l|}{ Year (ref: 2007) } \\
\hline 2008 & - & - & - & - & - & - & 0.05 & 0.02 & 1.96 & -0.04 & -0.03 & -3.07 \\
\hline 2009 & -0.07 & -0.05 & -5.25 & -0.18 & -0.07 & -7.46 & 0.16 & 0.09 & 6.88 & & & \\
\hline Household size & 0.01 & 0.02 & 2.02 & 0.04 & 0.04 & 2.19 & - & - & - & -0.04 & -0.11 & -7.93 \\
\hline \multicolumn{13}{|l|}{ Household structure (ref: sole person) } \\
\hline Couple with no kids & - & - & - & 0.10 & 0.04 & 2.21 & -0.10 & -0.05 & -3.60 & 0.04 & 0.04 & 3.50 \\
\hline Couple with kids & - & - & - & 0.24 & 0.09 & 3.82 & -0.08 & -0.04 & -2.43 & - & - & - \\
\hline Single parent & - & - & - & 0.24 & 0.04 & 3.16 & - & - & - & - & - & - \\
\hline Other & - & - & - & 0.18 & 0.04 & 2.80 & -0.11 & -0.03 & -2.76 & - & - & - \\
\hline \multicolumn{13}{|l|}{ Home ownership (ref: owner) } \\
\hline Rented & - & - & - & -0.14 & -0.04 & -4.08 & 0.08 & 0.03 & 3.01 & - & - & - \\
\hline Other & - & - & - & -0.72 & -0.02 & -1.98 & - & - & - & - & - & - \\
\hline \multicolumn{13}{|l|}{ Type of dwelling (ref: separate house) } \\
\hline Flat or apartment & - & - & - & -0.12 & -0.02 & -2.36 & - & - & - & 0.08 & 0.04 & 3.86 \\
\hline Townhouse & - & - & - & -0.15 & -0.03 & -2.89 & - & - & - & 0.05 & 0.03 & 2.47 \\
\hline Other & - & - & - & & & & & & & 0.39 & 0.03 & 3.17 \\
\hline Number of cars in household & & & & 0.04 & 0.03 & 2.93 & -0.05 & -0.04 & -4.19 & - & - & - \\
\hline Number of motorbikes in household & 0.07 & 0.02 & 2.23 & - & - & - & - & - & - & 0.05 & 0.02 & 2.29 \\
\hline Number of bicycles in household & 0.03 & 0.06 & 5.23 & - & - & - & - & - & - & 0.04 & 0.11 & 9.37 \\
\hline Age (continuous) & -0.01 & -0.09 & -6.43 & - & - & - & - & - & - & -0.01 & -0.05 & -3.46 \\
\hline Female (ref: male) & - & - & - & - & - & - & 0.06 & 0.03 & 2.91 & -0.04 & -0.04 & -3.89 \\
\hline Country of birth: other (ref: Australia) & - & - & - & - & - & - & - & - & - & 0.02 & 0.02 & 2.11 \\
\hline Car licence: yes (ref: no) & - & - & - & 1.43 & 0.22 & 22.78 & -0.85 & -0.18 & -17.22 & -0.26 & -0.10 & -9.60 \\
\hline Motorbike licence: yes (ref: no) & - & - & - & - & - & - & -0.08 & -0.03 & -2.52 & - & - & - \\
\hline Other licence: yes (ref: no) & - & - & - & 0.13 & 0.03 & 2.74 & - & - & - & - & - & - \\
\hline Licence: some licence (ref: no licence) & - & - & - & - & - & - & - & - & - & - & - & - \\
\hline \multicolumn{13}{|c|}{ Personal income in week (ref: $\$ 1,600$ and higher) } \\
\hline$\$ 1,000-\$ 1,599$ & -0.13 & -0.07 & -4.94 & - & - & - & -0.13 & -0.05 & -3.66 & -0.05 & -0.04 & -2.45 \\
\hline$\$ 600-\$ 999$ & -0.26 & -0.15 & -10.00 & - & - & - & -0.21 & -0.10 & -6.16 & -0.08 & -0.07 & -4.41 \\
\hline$\$ 0-\$ 599$ & -0.36 & -0.25 & -13.26 & -0.15 & -0.06 & -5.11 & -0.24 & -0.13 & -6.56 & -0.08 & -0.07 & -3.74 \\
\hline Zero or negative income & -0.22 & -0.06 & -4.91 & - & - & - & -0.30 & -0.06 & -5.08 & -0.08 & -0.03 & -2.40 \\
\hline \multicolumn{13}{|l|}{ Employment status (ref: non-working) } \\
\hline Full time & 0.09 & 0.06 & 3.96 & 0.27 & 0.11 & 8.27 & 0.07 & 0.03 & 2.64 & -0.15 & -0.14 & -9.22 \\
\hline Part time & 0.13 & 0.06 & 5.27 & 0.33 & 0.09 & 8.68 & - & - & - & -0.09 & -0.06 & -5.30 \\
\hline Casual & 0.12 & 0.04 & 3.76 & 0.21 & 0.04 & 4.02 & - & - & - & - & - & - \\
\hline$F$ & & & 77.37 & & & 82.21 & & & 35.13 & & & 24.37 \\
\hline$R^{2}$ & & & 0.09 & & & 0.13 & & & 0.05 & & & 0.04 \\
\hline$N$ & & & & & & & & & & & & 9,766 \\
\hline
\end{tabular}

Dashed coefficients are not significant at the 0.05 level

affects both the global (e.g. climate change) and local (e.g. air pollution) environments and thus is one of the major contributing factors to unsustainable urban development (Alam et al. 2006; Yigitcanlar and Dur 2010; Yigitcanlar and Teriman 2014). Climate change is one of the most important policy challenges facing the world population caused by the increase in greenhouse gases in the atmosphere, and the most prominent contributor to climate change is the burning of fossil fuels (Line et al. 2010; Liao et al. 2013). Globally, transport is responsible for $24 \%$ of 
greenhouse gas (GHG) emissions, and more importantly, despite policy efforts worldwide, an increasing rate of GHG emissions has been evident from this sector (Marsden and Rye 2010). Moreover, estimates show that transport energy usage will continue to increase at a rate of about $2 \%$ per year worldwide, whilst total transport energy usage and carbon emissions will be $80 \%$ higher than their current levels by 2030 (Xia et al. 2013). Note also that nearly $85 \%$ of transportation-related GHG is exhausted by land transportation, and a significant share of this is attributed to the personal road transport sector (Meyer et al. 2007; Hickman et al. 2010).

At local level, vehicle emissions are a significant source of air pollution, especially in car-dependent cites. For example, road transport accounts for about $42 \%$ of total NOx (oxides of nitrogen), $47 \%$ of total carbon monoxide (CO), and $18.4 \%$ of total particulate matter (PM) emissions in the member states of European Union (Xia et al. 2013). Again, the increase in personal travel has been identified as the main contributing factor to the increasing level of pollution in cities. Research has shown that current travel behaviour is unsustainable: people are travelling further and for longer, car ownership has increased, whilst car occupancy has dropped (Howarth and Polyviou 2012). Worries about the environmental impact of travel has resulted in a focus attention on how people might be persuaded to use public transport more and private car travel less (Guiver 2007). This is due to the fact that although public transport is not defined as a 'zero-pollutant' travel mode, its average emissions per passenger are far lower than that from cars. A number of studies have identified that a notable share of the driving is by choice rather than necessity (Handy et al. 2005; Line et al. 2010). As a result, as much as $40 \%$ of the car journeys could be reduced and as many as $80 \%$ could be replaced simply by maximising the use of alternative means of transport (Stradling 2003). Consequently, a number of soft policy measures in the form of personalised travel planning (e.g. workplace travel planning, school travel planning, information and marketing, car clubs, car cooperatives, tele-working, tele-conferencing, shopping from home) have been applied with relative success in various contexts (Cairns et al. 2008; Yigitcanlar and Lee 2014). In addition, a positive impact of system level changes (e.g. increasing accessibility to opportunities and services) has also been documented in the literature (Howarth and Polyviou 2012).

Unlike the assessment of travel behaviour changes, a direct measure of the environmental impacts of both the soft and hard policy interventions is relatively rare in the literature (Tuzkaya 2009). However, based on the findings from other studies, it is possible to deduce that travel behaviour change will have an immediate impact on the environment. For example, car use restriction during the
2008 Beijing Olympic Games resulted in a higher level of PT and AT usage which consequently reduced a significant amount of pollutants in the city (e.g. the average reduction rates of $\mathrm{PM} 10, \mathrm{CO}, \mathrm{NO} 2$, and $\mathrm{O} 3$ were 28, 19.3, 12.3, and $25.2 \%$, respectively) (Wang and Xie 2009). A similar finding has been reported for the 1996 Atlanta Olympic Games (Xia et al. 2013). In addition to the environmental benefits, numerous studies have identified a number of policy co-benefits of alternative transport usage. For example, travel behaviour affects physical and mental health of people, including cancer, cardiovascular disease, vehicle crashes, and diabetes, four major causes of death (Litman 2013). Additionally, walking to and from public transportation may help to achieve the recommended level of physical activity in a day for many people (Besser and Dannenberg 2005). In addition, both PT and AT usage facilitate social interaction and thereby increase trust and reciprocity (Currie and Stanley 2008; Stanley et al. 2012).

Based on the previous discussion and the findings reported in this paper, it is reasonable to say that the GFC has resulted in an improved in ambient air quality, reduced GHG emissions, improved health of people, and helped build social capital. However, to what extent are these outcomes desirable as a consequence of the GFC? These are discussed further in the following concluding section.

\section{Conclusion}

The GFC, as documented in the literature, has two levels of outcomes: immediate and ultimate. The immediate outcomes of the GFC are the loss of employment and reduced level of income, amongst others. The consequences (ultimate outcomes) of these immediate outcomes have further been investigated in a number of policy sectors (e.g. tourism, health, and housing). However, unlike other sectors, relatively little is known about the influence of the GFC on the transport sector in general and travel behaviour in particular at the household/individual level. Speculation prevails that lack of related datasets have hindered research at this level of disaggregation in the transport sector (Yang and Timmermans 2011). To the knowledge of the authors, this is the first study to utilise multiples sources of disaggregate data collected at the individual level to investigate the impacts of the GFC on travel behaviour. This research employs panel data from a representative sample from Brisbane, Australia, where the GFC had comparatively small but significant effects on the economy. This dataset captures the socio-economic and lifecycle changes of individuals (e.g. loss of job, retirement, reduced income, increased care responsibility) over the GFC periods (2007-2009). These changes, therefore, relate to the immediate outcomes of the GFC. The dataset also contains 
mode choice of people both pre- (2007) and post-GFC (2009) periods. A combination of these two datasets enabled an evaluation of the influence of the GFC in transport sector-i.e. mode switching behaviour. The research also covers the aggregated impacts of the GFC in terms of changes in the number of trips made and time spent travelling by modes based on repeated cross-sectional household travel survey data. The analyses presented in this paper indicate that the GFC significantly influenced people to switch to more environmentally friendly travel modes, irrespective of the indicators used. For example, people who lost their jobs or whose income reduced switched to PT. Similarly, people spent significantly less time using the LEFT (e.g. car, taxi) in 2009 compared to 2007 and, in contrast, spent more time using the PT. However, the overall difference in terms of time spent for travelling remained significantly lower in 2009 , so did the number of trips made both in 2008 and 2009.

During the GFC, people seemed to switch to more environmentally friendly travel modes for three reasons. First, the GFC takes an economic toll on some households, forcing them to adopt more economically viable travel modes. Second, it constrained the mobility of individuals through reduced discretionary income (e.g. fewer trips, less time invested in travelling) translating to reduced time spent travelling. These impacted travellers faced the risk of being excluded from society (Social Exclusion Unit 2003; Duvarci et al. 2011; Hine et al. 2012). Third, some people behave more cautiously and economically not because they experienced a lower level of income or lost their jobs but due to the fear of uncertainty (i.e. fear of losing job and thereby to save money for the unknown future).

What are the policy lessons from the findings? The findings provide comprehensive evidence on how economically disadvantaged groups faced transport disadvantage in Australia during the period that includes the GFC. The different indicators paint a different picture of which groups were most affected. The findings can be used to develop group specific policy responses in similar crisis (e.g. concessionary PT card). Given that the crisis resulted in a higher demand/utilisation of PT service, therefore, transportation planners need to be equipped with another type of contingency plan (Meyer and Belobaba 1982). For example, transit agencies need to be prepared with storing older buses for crisis use. Numerous studies have identified that the biggest challenge for a mode switch is a lack of awareness about the availability and quality of PT services (Brög et al. 2009). The crisis forced people to use the PT, and therefore, it was an opportunity for transit agencies that could be exploited through demonstrating the quality of PT services (e.g. offering pleasant, seamless, and low-cost service). Research has shown that despite being forced to use PT services; and once begun, many people continued to do so, especially if they perceive few advantages to car use or more benefits to PT use, such as reliable service, access to new and interesting parts of the city, and productive and pleasant activities en route (Brown et al. 2003).

The findings in Brisbane, Australia, are likely to be on the low side of GFC impacts, as it has been affected less than many other similar sized cities in other countries. Thus, if effects can be seen in Brisbane, they are likely to be more pronounced in cities harder hit by the GFC. The effects observed were relatively short-term effectsincluding changes to travel behaviour and choice of modes and travel time. Longer-term effects could also be possible, such as residential relocation and selling and buying of more fuel efficient vehicles, reduction in cars owned, etc. This study examined the short-term effects of the GFC on travel behaviour, whilst the longer-term effects remain the topic of our future study.

Acknowledgments The authors would like to thank the Queensland Department of Transport and Main Roads (QDTMR) for the provision of Household Travel Survey Data Sets used in this research. We also acknowledge and cordially thank the editor and anonymous reviewers for their constructive comments and suggestions, which helped us to improve the manuscript. Gavin Turrell is funded by a National Health and Medical Research Council Senior Research Fellowship (ID 1003710).

\section{References}

Alam J, Alam B, Rahman M, Khan S, Munna G (2006) Unplanned urbanization: assessment through calculation of environmental degradation index. Int J Environ Sci Technol 3(2):119-130

Alsnih R, Hensher D (2003) The mobility and accessibility expectations of seniors in an aging population. Transp Res Part A Policy Pract 37(1):903-916

Besser L, Dannenberg A (2005) Walking to public transit: steps to help meet physical activity recommendations. Am J Prev Med 29(1):273-280

Bhat C, Guo J (2007) A comprehensive analysis of built environment characteristics on household residential choice and auto ownership levels. Transp Res Part B Methodol 41(1):506-526

Bittman M, Bradbury B (2012) Introduction to the themed section: children of the recession-the social consequences of an economic downturn. Aust J Soc Issues 47(1):479-483

Blakely T, McLeod M (2009) Will the financial crisis get under the skin and affect our health? Learning from the past to predict the future. N Z Med J 122(1):76-83

Brög W, Erl E, Ker I, Ryle J, Wall R (2009) Evaluation of voluntary travel behaviour change: experiences from three continents. Transp Policy 16(1):281-292

Bronner F, de Hoog R (2011) Economizing behaviour during travel: strategies and information sources used. J Vacat Mark 17(1):185-195

Brown B, Werner C, Kim N (2003) Personal and contextual factors supporting the switch to transit use: evaluating a natural transit intervention. Anal Soc Issues Public Policy 3(1):139-160

Buckley M (2012) From Kerala to Dubai and back again: construction migrants and the global economic crisis. Geoforum 43(1):250-259

Burton N, Haynes M, Wilson L, Giles-Corti B, Oldenburg B, Brown W, Giskes K, Turrell G (2009) Habitat: a longitudinal multilevel 
study of physical activity change in mid-aged adults. BMC Public Health 9(1):76-87

Cairns S, Sloman L, Newson C, Anable J, Kirkbride A, Goodwin P (2008) Smarter choices: assessing the potential to achieve traffic reduction using 'soft measures'. Transp Rev 28(1):593-618

Cao X, Mokhtarian P, Handy S (2007) Do changes in neighborhood characteristics lead to changes in travel behavior? A structural equations modeling approach. Transportation 34(1):535-556

Chatterjee K, Sherwin H, Jain J (2013) Triggers for changes in cycling: the role of life events and modifications to the external environment. J Transp Geogr 30(1):183-193

Chen C, Varley D, Chen J (2011) What affects transit ridership? A dynamic analysis involving multiple factors, lags and asymmetric behaviour. Urban Stud 48(1):1893-1908

Chesters J (2010) The global financial crisis in Australia. In: Velayutham S, Ebert N, Watkins S (eds) TASA 2010 Proceedings of the Conference: Social Causes, Private Lives. Australian Sociological Association, The University of Queensland, Australia

Colley L (2012) How did public services fare? A review of Australian state public service labour markets during the global financial crisis. J Ind Relat 54(1):612-636

Currie G, Delbosc A (2010) Exploring public transport usage trends in an ageing population. Transportation 37(1):151-164

Currie G, Delbosc A (2011) Exploring the trip chaining behaviour of public transport users in Melbourne. Transp Policy 18(1):204-210

Currie G, Phung J (2007) Transit ridership, auto gas prices, and world events new drivers of change? Transp Res Rec: J Transp Res Board 1992(1):3-10

Currie G, Stanley J (2008) Investigating links between social capital and public transport. Transp Rev 28(1):529-547

Curtis C, Headicar P (1997) Targeting travel awareness campaigns: which individuals are more likely to switch from car to other transport for the journey to work? Transp Policy 4(1):57-65

Dargay J (2007) The effect of prices and income on car travel in the UK. Transp Res Part A: Policy Pract 41:949-960

Dodson J, Sipe N (2008) Shocking the suburbs: oil vulnerability in the Australian city. UNSW Press, Sydney

Dur F, Yigitcanlar T (2014) Assessing land-use and transport integration via a spatial composite indexing model. Int J Environ Sci Technol. http://dx.doi.org/10.1007/s13762-013-0476-9

Duvarci Y, Yigitcanlar T (2007) Integrated modeling approach for the transportation disadvantaged. J Urban Plan Dev-ASCE 133(3): $188-200$

Duvarci Y, Yigitcanlar T, Alver Y, Mizokami S (2011) The variant concept of transportation disadvantaged: evidence from Aydin, Turkey and Yamaga, Japan. J Urban Plan Dev-ASCE 137(1):82-90

Eichengreen B (2011) Crisis and growth in the advanced economies: what we know, what we do not, and what we can learn from the 1930s. Comp Econ Stud 53(1):383-406

Gerrans P (2012) Retirement savings investment choices in response to the global financial crisis: Australian evidence. Aust J Manag 37(1):415-439

Guiver J (2007) Modal talk: discourse analysis of how people talk about bus and car travel. Transp Res Part A: Policy Pract 41(1):233-248

Hamilton J (2009) Causes and consequences of the oil shock of 2007-2008. Brookings Institution, Washington, DC

Handy S, Weston L, Mokhtarian P (2005) Driving by choice or necessity? Transp Res Part A: Policy Pract 39(1):183-203

Hensher D, Stanley J (2009) What if petrol increased to \$10 per litre in Melbourne? Implications for travel behaviour and public transport demand. Road Transp Res 18(1):61-68

Hickman R, Ashiru O, Banister D (2010) Transport and climate change: simulating the options for carbon reduction in London. Transp Policy 17(1):110-125
Hine J, Kamruzzaman M (2012) Journeys to health services in Great Britain: an analysis of changing travel patterns 1985-2006. Health Place 18(1):274-285

Hine J, Kamruzzaman M, Blair N (2012) Weekly activity-travel behaviour in rural Northern Ireland: differences by context and socio-demographic. Transportation 39(1):175-195

Holmgren J (2013) An analysis of the determinants of local public transport demand focusing the effects of income changes. Eur Transp Res Rev 5(1):101-107

Howarth C, Polyviou P (2012) Sustainable travel behaviour and the widespread impacts on the local economy. Local Econ 27(1):764-781

Ironmonger D (2012) Research note: what happened to time use during the global financial crisis? Aust J Soc Issue 47(1):527-540

Kamruzzaman M, Hine J (2012) Analysis of rural activity spaces and transport disadvantage using a multi-method approach. Transp Policy 19(1):105-120

Kamruzzaman M, Baker D, Washington S, Turrell G (2013) Residential dissonance and mode choice. J Transp Geogr 33(1):12-28

Kamruzzaman M, Baker D, Washington S, Turrell G (2014) Advance transit oriented development typology: case study in Brisbane, Australia. J Transp Geogr 34(1):54-70

Karanikolos M, Mladovsky P, Cylus J, Thomson S, Basu S, Stuckler D, Mackenbach J, McKee M (2013) Financial crisis, austerity, and health in Europe. Lancet 381(1):1323-1331

Kendig H, Wells Y, O'Loughlin K, Heese K (2013) Australian baby boomers face retirement during the global financial crisis. J Aging Soc Policy 25(1):264-280

Khoo H, Ong G, Khoo W (2012) Short-term impact analysis of fuel price policy change on travel demand in Malaysian cities. Transp Plan Technol 35(1):715-736

Koser K (2010) The impact of the global financial crisis on international migration. Whitehead J Dipl Int Relat 11(1):13-20

Krizek K (2003) Residential relocation and changes in urban travel: does neighborhood-scale urban form matter? J Am Plan Assoc 69(1):265-281

Lane B (2010) The relationship between recent gasoline price fluctuations and transit ridership in major US cities. J Transp Geogr 18(1):214-225

Lane B (2012) A time-series analysis of gasoline prices and public transportation in US metropolitan areas. J Transp Geogr 22(1):221-235

Liao C, Chang C, Su C, Chiueh P (2013) Correlation between landuse change and greenhouse gas emissions in urban areas. Int $\mathrm{J}$ Environ Sci Technol 10(6):1275-1286

Line T, Chatterjee K, Lyons G (2010) The travel behaviour intentions of young people in the context of climate change. J Transp Geogr 18(1):238-246

Litman T (2013) Transportation and public health. Annu Rev Public Health 34(1):217-233

Marsden G, Rye T (2010) The governance of transport and climate change. J Transp Geogr 18(1):669-678

Merkert R, Hensher D (2011) The impact of strategic management and fleet planning on airline efficiency: a random effects Tobit model based on DEA efficiency scores. Transp Res Part A: Policy Pract 45(1):686-695

Meurs H, Haaijer R (2001) Spatial structure and mobility. Transp Res Part D: Transp Environ 6(1):429-446

Meyer M, Belobaba P (1982) Contingency planning for response to urban transportation system disruptions. J Am Plan Assoc 48(1):454-465

Meyer I, Leimbach M, Jaeger C (2007) International passenger transport and climate change: a sector analysis in car demand and associated $\mathrm{CO}_{2}$ emissions from 2000 to 2050. Energy Policy 35(1):6332-6345 
Mountford H (2011) Oh won't you stay just a little bit longer: changing employers' views of older workers. Aust Bull Labour 37(1):164-190

Murphy L (2011) The global financial crisis and the Australian and New Zealand housing markets. J Hous Built Environ 26(1):335-351

Queensland Government (2010) South-East Queensland travel survey 2009: survey procedures and documentation v2.2-Brisbane Survey 2009. Queensland Transport and Main Roads, Brisbane

Redmond G, Patulny R, Whiteford P (2013) The global financial crisis and child poverty: the case of Australia 2006-2010. Soc Policy Adm 47(1):709-728

Saunders P, Deeming C (2011) The impact of the crisis on Australian social security policy in historical perspective. Soc Policy Adm 45(1):371-388

Saunders P, Wong M (2012) Estimating the impact of the global financial crisis on poverty and deprivation. Aust $\mathrm{J}$ Soc Issue 47(1):485-503

Scheiner J, Holz-Rau C (2013) A comprehensive study of life course, cohort, and period effects on changes in travel mode use. Transp Res Part A: Policy Pract 47(1):167-181

Smith M, Kauermann G (2011) Bicycle commuting in Melbourne during the 2000s energy crisis: a semiparametric analysis of intraday volumes. Transp Res Part B: Methodol 45(1):1846-1862

Social Exclusion Unit (2003) Making the connections: transport and social exclusion. Social Exclusion Unit, The Stationery Office, London

Stanley J, Stanley J, Hensher D (2012) Mobility, social capital and sense of community: what value? Urban Stud 49(1):3595-3609

Stradling S (2003) Reducing car dependence. In: Hine J, Preston J (eds) Integrated futures and transport choices: UK transport policy beyond the 1998 white paper and transport act. Ashgate, Aldershot, pp 100-115

Turner T, Niemeier D (1997) Travel to work and household responsibility: new evidence. Transportation 24(1):397-419

Turrell G, Haynes M, Burton N, Giles-Corti B, Oldenburg B, Wilson L, Giskes K, Brown W (2010) Neighborhood disadvantage and physical activity: baseline results from the Habitat multilevel longitudinal study. Ann Epidemiol 20(1):171-181
Tuzkaya U (2009) Evaluating the environmental effects of transportation modes using and integrated methodology and an application. Int J Environ Sci Technol 6(2):277-290

Van Cranenburgh S, Chorus C, Van Wee B (2012) Substantial changes and their impact on mobility: a typology and an overview of the literature. Transp Rev 32(1):569-597

Van der Waard J, Jorritsma P, Immers B (2013) New drivers in mobility; what moves the dutch in 2012? Transp Rev 33(1):343-359

Verick S (2012) Giving up job search during a recession: the impact of the global financial crisis on the South African labour market. J Afr Econ 21(1):373-408

Wang T, Xie S (2009) Assessment of traffic-related air pollution in the urban streets before and during the 2008 Beijing Olympic Games traffic control period. Atmos Environ 43(1):5682-5690

Washington S, Matthew K, Mannering F (2010) Statistical and econometric methods for transportation data analysis. Chapman \& Hall/CRC, Boca Raton

Xia T, Zhang Y, Crabb S, Shah P (2013) Cobenefits of replacing car trips with alternative transportation: a review of evidence and methodological issues. Journal of Environmental \& Public Health 2013(1):1-14

Yang D, Timmermans H (2011) Effects of energy price fluctuation on car-based individual activity-travel behavior. Procedia Soc Behav Sci 20(1):547-557

Yigitcanlar T, Dur F (2010) Developing a sustainability assessment model: the sustainable infrastructure land-use environment and transport model. Sustainability 2(1):321-340

Yigitcanlar T, Lee S (2014) Korean ubiquitous-eco-city: a smartsustainable urban form or a branding hoax? Technol Forecast Soc Change. http://dx.doi.org/10.1016/j.techfore.2013.08.034

Yigitcanlar T, Teriman S (2014) Rethinking sustainable urban development: towards an integrated planning and development process. Int J Environ Sci Technol. http://dx.doi.org/10.1007/ s13762-013-0491-X

Yigitcanlar T, Dodson J, Gleeson B, Sipe N (2007) Travel selfcontainment in master planned estates: analysis of recent Australian trends. Urban Policy Res 25(1):133-153 